\title{
Emergent Collaboration on Twitter: A Case Study of the \#BlackLivesMatter Movement
}

\author{
Daniel Lundgaard \\ Copenhagen Business School \\ dlu.msc@cbs.dk
}

\author{
Liana Razmerita \\ Copenhagen Business School \\ $\underline{\text { lra.msc@cbs.dk }}$
}

\author{
Chee-Wee Tan \\ Copenhagen Business School \\ ct.digi@cbs.dk
}

\begin{abstract}
This paper explores the organizing elements that foster emergent collaboration within large-scale communities on online social platforms like Twitter. This study is based on a case study of the \#BlackLivesMatter social movement and draws on organizing dynamics and online social network literature, combined with the analysis of 2050 tweets collected from days where the movement had high levels of activity. Drawing on the literature review, we propose a framework consisting of three organizing elements: structure, engagement, and communicative content that are essential in analyzing online collaboration. This paper uses this framework to analyze the collected tweets and identify how actors organize and engage in large-scale communities founded by emergent online collaboration. This paper identifies characteristics of how these key elements and a dynamic interplay between the two logics of action foster emergent collaboration in social movements using Twitter.
\end{abstract}

\section{Introduction}

Using social media, in particular Twitter, actors engage in large-scale, fluid communities that transcend time and space [3,4]. These large-scale communities comprise social networks of individuals that interact and collaborate based on solidarity and perceptions of shared values $[2,13,14,24,32]$. These communities can consist of millions of individuals, each with their own ideas and motives, utilize specific hashtags to engage in emergent collaboration through various social networks [2, 24]. Twitter's pivotal role in fostering these communities can be seen in the recent emergence of so-called "Twitter revolutions", which relates to the exploitation of Twitter as a focal social networking platform for inspiring and mobilizing social activism, for example the Tunisian revolution in 2010-2011 [23] and the Occupy Wall Street-movement in 2011 [3, 4]. Following the argument that social movements at their core are collectives of people unified in the pursuit of common goals based on a shared set of beliefs and a sense of belonging [11], these Twitter movements are analogous to virtual communities. Interestingly, online collaboration is often based on some form of personal interpretation [3, $22,24,29,38]$, as individuals interact, share ideas and personal stories that are enriched or articulated into communal knowledge [28], which in turn lead to cocreation of meaning [13].

Consequently, the purpose of this paper is to investigate the dynamics and organizing elements that foster emergent collaboration among millions of disparate individuals. This paper draws upon extant literature on social network $[2,13,21,30,32,37]$ as well as past studies on the emergence of new organizing dynamics [4, 31, 38], especially with respect to the two organizing logics: the logic of collective action [26] and the logic of connective action [3]. We endeavor to shed light on these organizing elements by addressing the research question below:

What are the key organizing elements that foster emergent collaboration in large-scale online communities?

This paper contributes to contemporary research on online collective action $[3,4,23,38]$, and the role of Twitter in fostering collaboration [16, 19, 31] by proposing a framework embodying three organizing elements: structure, engagement and communicative content, as well as by unraveling the dynamic interplay between the two archetypes of organizing logics.

\section{Theoretical background}

\subsection{Organizing logics}

Within online communities, we can distinguish between two archetypes of organizing logics, namely logic of collective action [26] and logic of connective action [3].

The logic of collective action [26] is based on the premise that "rational self-interested individuals will not act to achieve their common or group interests" 
[26:2]. Collaboration towards a common good thus requires more formal organization, which in turn demands stronger commitment by the individual, and will often culminate in collective identity framing [3, 23, 26]. Communities, which reflect this logic of collective action, also tend to be characterized by more homogenous social networks. The homogenous social network is defined by values and symbols unique to that network [23] and the collective identity framing is often centered on these values and symbols [23]. These homogenous social networks often attempt to bring members and associated social networks into action and collectively forge a common cause through interactions and shared communicative content. Collective action also inspires stronger commitment and the adoption of more self-changing social identities, which is crucial for social movements to achieve results [17].

The internet, especially with the rise of social media, has affected how individuals organize themselves in the pursuit for social change through its ability to facilitate social interactions [7, 32], [6, 8]. The internet encourages organizational hybridity, which describes the organizational change among traditional interest communities as they adapt to digital technologies that facilitate more complex spatial and temporal interactions [6]. This organizational change has been investigated by Bennett \& Segerberg [3], which led to the framing of the logic of connective action. The logic of connective action holds that actors organize in large-scale communities through digitally networked action with little or no institutionalized control. These communities are constituted by individuals that rely on personal action frames in the interactions, seeing that connections between likeminded individuals within connective action, as opposed to those within collective action, do not require a strong commitment or the construction of a united 'we' [3]. The argument that we live in a participatory digital culture [20, 37] is crucial, as the act of sharing is a linchpin of connective action. The act of sharing is essential as participation becomes self-motivating due to how the personally expressive content is shared and recognized by others, who in turn, respond by remixing the shared content based on their own personal interpretation. This act of sharing then becomes an act of personal expression and selfvalidation by contributing to perceptions of common good based on personalized action frames, which in turn acts as legitimization processes [3, 8, 23]. The reliance on personal action frames to share more personalized content is often seen in the form of personal stories or memes [9], which can be readily disseminated on social platforms [3, 23, 38].

\subsection{Collaboration on online social platforms}

Online social platforms, especially social media, have revolutionized what it means to interact, share, and engage in collaborations through synergetic articulation of personal experience into collective knowledge [28, 30]. Social action is moving from traditional collective action towards digitally constituted networked action [8], where social platforms enable actors to individually self-organize in social networks. The centrality of Twitter can be attributed to the support for ad-hoc network formation based on its stitching mechanisms [4] that Bennett et al. defines as "particular communication technologies and practices ... that connect different networks into coherent organization" [4:234]. These stitching mechanisms thereby also dictate the ways in which actors interact and collaborate within these social networks. The stitching mechanisms of Twitter facilitate quick dissemination and diffusion of content across cultural and geographical boundaries as interactions are founded on shared interest and values rather than the reciprocal 'friending' that can be seen on Facebook. The fluid organization of actors that selforganize in online social networks is however argued to become chaotic and unproductive and never amount to anything [17]. We contend that the structure and organizational coordination of social networks within the community is a decisive element that can support emergent collaboration.

To identify the organizing elements supporting emergent collaboration, we need to further consider the incentives for participating in online communities, which we refer to as Engagement. Individuals seldom make long-standing commitments and instead, engage in fluid collaboration or fleeting causes with less initial commitment $[6,13]$, often with a focus on the pursuit of self-interests [30]. Engagement often take place in short-lived social networks and communities that are formed to pursue rapidly shifting particular issues [6, $13,19]$. Prior research has however found that people voluntarily participate in emergent collaboration [21, 25]. This supports the argument that we are witnessing the emergence of online communities that are leaning towards collaboration as a mere avenue for information dissemination [13]. A common cause or shared belief in a narrative is essential in mediating solidarity among thousands, if not millions of diverse actors [2, 13]. The common cause is essential as it inspires solidarity and coherence, both of which constitute desirable attributes in organizing actors in pursuit of common goals [13, 21]. Interestingly such common causes are often a mental construct, an informal entity that "glues" individuals together, but only exist in their minds [2, 14]. This is highly relevant as there is a distinct 
difference in whether engagement is defined by the pursuit of self-interests, or actors who consciously target a common goal. These two distinctions might however not be mutually exclusive, as Schneckenberg [30] finds that even though participation is based on the pursuit of self-interests, the actions of the individual sometimes serve the collective as an unconscious side-effect. Engagement thus comprises both individual motives and social incentives that have a significant impact on emergent collaboration.

Engagement is often based on responding to or replicating the shared content of others. This enables collaboration as a wide array of individuals with different ideas, expertise and from multiple contexts are brought together [39]. We contend that investigating the characteristics of the shared communicative content is central to understanding the elements that foster emergent collaboration. Investigating the communicative content is crucial as the use of pronouns reveals information about the ways people think, feel, and connect with others [27]. The communicative content on online social platforms is often seen in the form of memes that have become an easy way for various actors to customize content and share it across geographical and cultural boundaries. Memes are a catalyst for cultural developments [37]. Memes are defined as a symbolic package, an idea, behavior, style or a 'move' - and can be seen in the form of narratives, images, sound cues or specific actions [9, 37]. Memes are characterized by being easily transferrable, remixed, imitated, adapted and sufficiently open for interpretation by others. This in turn allows a wide array of people to support it - albeit for different reasons. Memes are however also argued to threaten the independence of thought within online social networks, as the constant reiteration and remix of content can resemble a closed loop where the same content is recycled [36].

\subsection{Organizing elements of online social networks}

From our review of extant literature three key organizing elements are identified as central in analyzing emergent collaboration in online social networks. These organizing elements are: structure, engagement, and communicative content (see Table 1).

\begin{tabular}{|c|c|c|}
\hline \multicolumn{3}{|c|}{ Table 1: Organizing Elements } \\
\hline & Collective Action & Connective Action \\
\hline 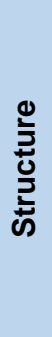 & $\begin{array}{l}\text { The structure resembles } \\
\text { strong formal } \\
\text { organizational } \\
\text { coordination within } \\
\text { social networks based } \\
\text { on specific values and } \\
\text { symbols }\end{array}$ & $\begin{array}{l}\text { The structure is defined } \\
\text { by actors that self- } \\
\text { organize without } \\
\text { central leadership in } \\
\text { large-scale fluid } \\
\text { communities defined by } \\
\text { a pursuit for rapidly } \\
\text { shifting issues }\end{array}$ \\
\hline 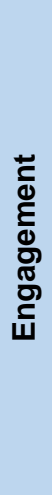 & $\begin{array}{l}\text { Actors engage by } \\
\text { collectively seeking a } \\
\text { common cause through } \\
\text { stronger commitment } \\
\text { by constructing a united } \\
\text { "we" based on shared } \\
\text { values specific to the } \\
\text { social network }\end{array}$ & $\begin{array}{l}\text { Engagement is self- } \\
\text { motivating, often based } \\
\text { on a pursuit for self- } \\
\text { interests and rapidly } \\
\text { shifting issues, where } \\
\text { reusing the shared } \\
\text { content of others } \\
\text { legitimizes the pursuit } \\
\text { for self-interests } \\
\text { without the } \\
\text { construction of a united } \\
\text { "we" }\end{array}$ \\
\hline 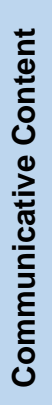 & $\begin{array}{l}\text { Content is influenced } \\
\text { by collective action } \\
\text { frames that are co- } \\
\text { created through } \\
\text { continuous interaction } \\
\text { based on a collective } \\
\text { interpretation of the } \\
\text { perceived shared values } \\
\text { related to the specific } \\
\text { social network }\end{array}$ & $\begin{array}{l}\text { Content is characterized } \\
\text { by the use of } \\
\text { personalized action } \\
\text { frames - often } \\
\text { communicated through } \\
\text { personal stories or } \\
\text { memes that are easily } \\
\text { remixed, transferred } \\
\text { and sufficiently open } \\
\text { for interpretation }\end{array}$ \\
\hline
\end{tabular}

\section{Methodology}

\subsection{Case study}

We conduct a qualitative content analysis based on a case study [40] of the \#BlackLivesMatter movement, which in 2014, became prominent as millions of individuals collaborated in an attempt to change the world [18, 33]. The case study is chosen as it focuses on deciphering and analyzing complex conditions related to specific events and occurrences presented within a single setting [12]. This case study seeks to obtain an invaluable and deep understanding of the organizing elements by examining the real-world contexts and the complex conditions that define them. We collected empirical data directly from the Twitter feed and from secondary data (e.g. blogs, forums, news sites and media) as well as various discussions about 
how social media is altering individuals' pursuit of social change.

\subsection{Case description: \#BlackLivesMatter}

The \#BlackLivesMatter hashtag originates from the Black Lives Matter movement, which particularly in the states, raised awareness and inspired rallies as well as protests nationwide. The use of \#BlackLivesMatter started in 2013 after the acquittal of George Zimmerman in the shooting of African-American teenager Trayvon Martin [10] but did not attract greater awareness until late 2014. The movement seeks social change regarding racism and inequality by campaigning against violence towards black people based on the central narrative "stop killing us" [15]. \#BlackLivesMatter was ratified in January 2015 when the American Dialect Society declared \#BlackLivesMatter their Word of the year [10], and when TIME Magazine put Black Lives Matter as number four in naming the Person of the year [1]. The movement also became a relevant topic later in the American 2016 presidential election and was successful in raising awareness about institutional racism in general.

The \#BlackLivesMatter community is chosen for this case study, as various secondary data sources [10, 15, 33] suggest that \#BlackLivesMatter has become one of the most influential hashtags for pursuing social change. The \#BlackLivesMatter-hashtag is associated with other sub-movements such as \#Ferguson, \#ICantBreathe and \#IfTheyGunnedMeDown, thereby suggesting that \#BlackLivesMatter is pivotal in organizing online social networks to pursue common goals and thus represents a significant potential for identifying the organizing elements. The community exists primarily on Twitter, but can also be found on other social media platforms [15]. Data from the Black Lives Matter movement furthermore illustrates that \#BlackLivesMatter is the most used hashtag that does not refer to a single event [15], which is why that specific hashtag is chosen to investigate the community.

\subsection{Data collection and coding process}

The empirical data is collected during a three-day period when the \#BlackLivesMatter movement experienced high levels of activity and gained awareness as a consequence [15]. Secondary data sources (e.g. other reports, research articles and news sites) were extracted to determine the periods of high levels of activity, as Twitter only keep hashtagstatistics available for thirty days [35]. In total 2,050 tweets were gathered from 1,552 unique participants.
The dataset covers available Twitter interactions by searching for the specific hashtag, \#BlackLivesMatter, on the days with high levels of activity [35]. The data was gathered by opening a Twitter feed for the chosen periods of time and copying as many tweets as Twitter's APIs allowed [35], which resulted in slight discrepancies in the amount of collected tweets from the different days. The data is elicited without any interference from the researchers as the interactions took place already and it is assumed that the available tweets reflect the actual way the actors organize and the associated organizing elements of emergent collaboration. 635 tweets are collected from November $24^{\text {th }}$ where the increased activity is closely related to the decision of a grand jury to not indict Darren Wilson, the cop that shot and killed African American teenager Michael Brown. 717 tweets are collected from December $3^{\text {rd }}$ when hashtag usage increased as a grand jury decided not to indict the cop deemed to be responsible for the death of Eric Garner. Finally, 698 tweets are collected from December $13^{\text {th }}$ where usage of the hashtag spiked due to multiple simultaneous Black Lives Matter-protests across USA.

Thematic analysis was employed to analyze the data [5]. Thematic analysis is a data-driven technique that is often used to identify patterns and develop appropriate codes. Adhering to thematic analytical procedures, we conducted a preliminary analysis based on the collected data and secondary data sources (e.g. blogs, forums, news sites and media), to identify relevant patterns and re-occurring themes. Findings from the preliminary analysis were then employed to pinpoint the coding categories to be utilized in content analysis. The coding categories are therefore presumed to be representative, even if random samples were collected from other periods of the movement. The coding process is based on the textual content of the tweets, but also took into consideration the images and videos that were available in the raw data and the Twitter-feed. All tweets have been coded manually via NVivo 11.

\section{Data analysis}

The coding process identified five relevant categories. Tweets categorized as Disagreement or Irrelevant are omitted from the data analysis due to their low amount and relevance to the analysis of emergent collaboration. 


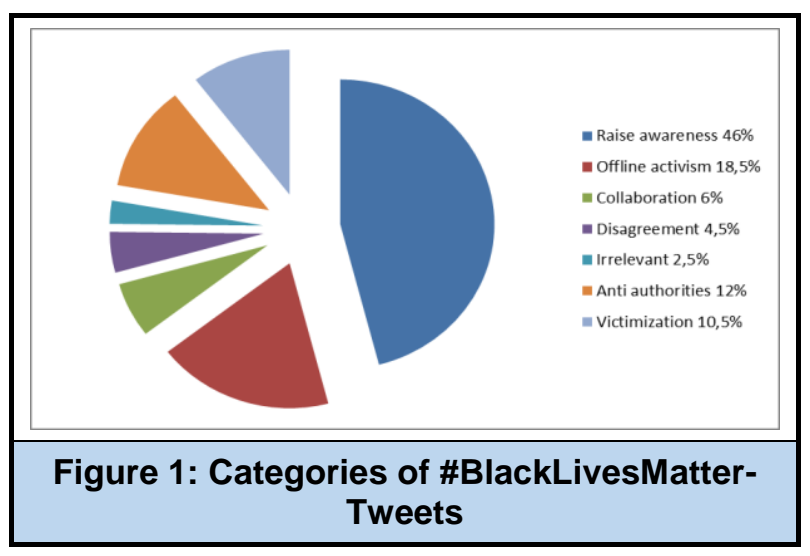

Raise awareness $(46 \%)$ - This category of tweets seeks to raise awareness about the persistence of the experienced issue. This category consists of tweets quoting famous - often black - individuals, links to relevant news articles and statements regarding the situation that black people experience. This type of tweets is often just an image, link or quote and the \#BlackLivesMatter hashtag. Tweets regarding future happenings and events are also found in this category as they seek to raise awareness about upcoming events.

"Akai Gurley and Tamir Rice. Two names you should know. \#BlackLivesMatter"

"\#BlackLivesMatter The People Must Know before they can act....Ida B. Wells"

Offline activism (18.5\%) - The second category covers tweets that describe or reference offline activism and often contain images or videos from rallies, protests or "die-in's". These tweets also seek to raise awareness, but do it by reporting live from protests. These tweets differentiate from raise awareness-tweets by either "reporting" from events or supporting those who went instead of simply raising awareness about their existence.

"So proud of my friends in @GWUPSU and $@$ GWRoosevelt for their protest today in Kogen. \#GWFerguson \#BlackLivesMatter"

"Standing on $16^{\text {th }}$ St with our friends and kids, vigil for racial justice. \#BlackLivesMatter"

Anti-authorities (12\%) - This category of tweets is more specifically targeted at police brutality and seeks to raise awareness by arguing that authorities are the cause of this issue. This is a more aggressive approach than the general statements found in the raise awareness-category, as they specifically target authorities. Tweets in this category also challenge the narrative shared in mainstream media as well.

"43 cops died in line of fire 2012. By contrast, here's over 90 killer cops for November this year. \#BlackLivesMatter"
"So when cops approached \#TamirRice they didn't realize a CHILD can be subdued w/out bullets? \#BlackLivesMatter"

Victimization (10.5\%) - These tweets seek to raise awareness about the general issue of black people being victims of institutional racism. The focus in this category is more on how black people are the victims of racism, than how authorities are the perpetrators.

"History proves that they have always been valued least So please acknowledge \#BlackLivesMatter" "It's so sad to hear about Tamir Rice. Black children don't get to be treated like children. \#blacklivesmatter"

Collaboration $(6 \%)$ - This category covers the tweets that seek to either raise awareness or social change through collaboration and joint effort rather than simply raising awareness. These tweets acknowledge the importance of collaboration by sharing relevant links, discussing protests tactics, sharing guidelines for "white allies" or start general discussions about how to raise awareness or how to move forward and through joint effort pursue a greater good.

"\#BlackLivesMatter protests are heating up across the US But which protest tactics are most effective?"

"It's time we discuss how to get involved in moving forward. Join us, CAPSU, and LAL tomorrow! \#BlackLivesMatter"

The collected tweets furthermore often reference other hashtags used by participants of the movement: \#AkaiGurley (82), \#MikeBrown (81), \#EricGarner (46) and \#TamirRice (44), are some of the most used names, while \#Ferguson (416), \#ICantBreathe (67) and \#HandsUpDontShoot (39) are the most used hashtags referencing other parts of the BlackLivesMatter movement.

\subsection{Findings}

The structure supporting emergent collaboration is defined by the technological affordances of the platform in the likes of hashtags, which function as organizing mechanisms. These affordances facilitate digitally networked action, which define how actors organize and share content. The stitching mechanisms are at the core of fostering emergent collaboration, as they enable interactions among actors in large-scale dynamic communities that transcend cultural and geographical boundaries. This is further substantiated by the large amount of unique voluntarily participating actors (1,552 unique participants sharing 2,050 tweets) across all five categories. The influence of hashtags 
can be seen how more than 775 hashtags related to \#BlackLivesMatter was found in the collected data, where especially \#Ferguson with 416 references stands out as a social network within the community.

"We are all \#Ferguson! \#BlackLivesMatter"

Hashtags facilitate collaboration between likeminded individuals across boundaries, which enable self-organizing digitally networked action as often seen in connective action, where the absence of formal organization enables different technological affordances to function as organizing mechanisms.

"You ALL are capable of leading and organizing. Keep the passion going. Email MU4MikeBrown@gmail.com to help organize \#BlackLivesMatter"

The analysis of the tweets within the antiauthorities, victimization, and collaboration categories suggests the existence of more committed like-minded actors who are embedded in more homogenous social networks.

"We Speak Their Names: 4 the \#Black \#Trans \#Women Murdered This Year ... \#BlackLivesMatter \#Equality4All \#lgbtqia”

These social networks mediate solidarity and facilitate a collective pursuit for common causes. This cultivates coherence among disparate actors who selforganize in homogenous social networks defined by values and symbols unique to that social network. This evidence illustrates the presence of stronger organizational coordination and traces of collective action.

Engagement in emergent collaboration is influenced by a pursuit of self-interests, as seen in the offline activism and raise awareness-categories where select participants focused on encouraging others to endorse and validate their engagement as a way to contribute to the common cause.

"RT if you think that \#BlackLivesMatter"

Engagement thereby became self-motivating, as reusing content when participating by responding to the shared content of others validated a pursuit for selfinterests and functioned as the context that legitimized engagement, which illustrates traces of the connective action in the way actors participated.

"Wipe the \#Mayonnaise out of your eyes. This is the original photo. Save it, use it, share it. \#BlackLivesMatter",

Interestingly, the common cause also incentivized engagement, as it became a context that legitimized the pursuit for self-interests by echoing perceived shared values. This indicates that actors not only pursued selfinterests, but also contributed to a collective pursuit for a common cause. This is substantiated by the 147 interactions with the use of "we" as a pronoun, which suggests a more collective engagement based on the co-creation of a united "we", which also fosters emergent collaboration e.g.

"As blacks we could go out here tonight holdings hands singing "kum ba yah my lord" and still be deemed dangerous \#Ferguson \#BlackLivesMatter"

This co-creation of a collective identity fosters emergent collaboration, as the collective identity mediates solidarity. This united 'we' thereby facilitates a collective pursuit for social change as seen in collective action. e.g

"This Stops Today. We Don't want to live this way. \#BlackLivesMatter \#tamirrice”

This collective pursuit for social change is furthermore seen in the offline activism-tweets, where individuals share their attendance at rallies, vigils, "die in's" and demonstrations.

"It's going down tomorrow. We will be heard.

\#BlackLivesMatter \#icantbreathe

\#handsupdontshoot"

Communicative content that can be easily shared and remixed is essential in supporting emergent collaboration. This is due to ease by which such contents could be adapted, imitated and easily transferred across cultural and geographical boundaries. This is for example seen in the use of quotations e.g.

"\#BlackLivesMatter The People Must Know before they can act.... Ida B. Wells,"

The shared content is often influenced by the use of personalized action frames. This is evidenced in how memes and personal stories function as a vehicle for interacting and engaging in collaboration by imitating and replicating the shared content of others. Personalizing the shared content therefore facilitates emergent collaboration between disparate actors e.g.

"I support the protestors of \#Ferguson because I was raised in St.louis and I have a young son, nieces, and nephews \#BlackLivesMatter"

Further analysis of the content within the collaboration, victimization, and raise awareness, categories illustrates that continuous collaboration by sharing content that echoes perceived shared values inspires the articulation of personalized action frames into collective action frames, which indicates traces of more collective action. The use of collective action frames foster coherence and reinforce a belief in the shared values. The perceived shared values then influence the way content is remixed, as for example seen in how the narrative "stop killing us" influences the shared content.

"You're tired of \#BlackLivesMatter trending? We're tired of innocent POC dying. And will keep talking about it because black lives MATTER" 


\section{Discussion of findings}

Findings suggest the existence of certain patterns and co-occurrences in the community that illuminates how features of the organizing logics influence the way the organizing elements foster collaboration. The Structure is found to be defined by the co-existence of elements from both logics of action. This substantiates and expands Bennett \& Segerberg's [3] argument that organizational structures are based on a hybrid of the two organizing logics archetypes. The features of collective action can in particular be discerned from the existence of a united "we" and the shared values that define the homogeneity of the social networks. The effect of connective action can be detected in how these homogenous social networks become associated through a perceived pursuit of common goals. Such associations among similar homogenous social networks can for example be seen in how victims' names and specific events had their own hashtags and were defined by shared symbols e.g. \#ICantBreathe and \#MikeBrown. These social networks were then connected, through the stitching features that function as organizing mechanisms, within a large-scale community. This finding supports the relevance of the stitching mechanisms as argued by Bennett et al. [4].

The co-existence of the two organizing logics is a result of how the internet encourages organizational hybridity as alleged by Chadwick [6]. The \#BlackLivesMatter movement illustrates this organizational hybridity, as the dynamic interplay between connective and collective action influences how the community is organized. This dynamic interplay is fostered by the social platform that promotes novel methods of interaction across cultural and geographical boundaries. These new ways of interaction are vital in fostering emergent collaboration and co-creation of meaning within a dynamic largescale fluid community. The importance of these new ways of interaction is especially evident from how connections are not only forged among like-minded actors in similar social networks defined by unique values, but also among several of these similar and homogenous social networks within a large-scale community. This association of disparate actors and causes within a large-scale community corroborates the argument of Wright [38] that we are seeing a shift from organizations organizing towards individuals selforganizing in interest-based collectives. The structure that fosters emergent collaboration is thus dependent on a certain level of organizational hybridity, as it enables dynamic co-creation of meaning, collective identities and shared values in homogeneous social networks within a large-scale community.
The interplay between both logics of action also influenced Engagement, as actors were observed to simultaneously participate by pursuing self-interests, as well as collectively pursuing a common cause. This is also a consequence of the multiple ways actors contribute, which can be discerned from the five different categories of tweets.

The notion of a common cause is at the core of engagement, as it became a mental construct that fostered emergent collaboration, which supports the arguments of Ardichvili et al. [2] and Fournier \& Lee [14]. Perceptions of common cause foster collaboration as individuals engaged by reusing shared content that contributes to the common cause, such as memes based on perceived shared values and narratives. This culminated in emergent collaboration defined by individuals that pursued self-interests in short-lived social networks related to specific events as suggested by Chadwick [6], Fenton [13] and Hu \& Hong [19]. Interestingly the reuse and imitation of others' shared content enabled this collaboration to simultaneously validate and legitimize the participation of others and thereby contribute to the common cause. In other words, the common cause enables voluntary participation based on a pursuit of self-interest to function as a vehicle for engaging in emergent collaboration defined by a greater purpose, which corroborate the argument of Schneckenberg [30].

The engagement in the collective pursuit for common causes is seen in the use of "we", which is consistent with the argument of Pennebaker [27] that our use of pronouns tells a lot about how we feel and connect, indicates the existence of a collective identity that is continuously co- and re-created by the way individuals engage. The co-creation of a collective identity is crucial as it inspires stronger commitment in the homogenous social networks and continuous engagement in emergent collaboration by facilitating a collective pursuit for something better than any actor could have achieved individually. The homogeneous social network thereby mediated solidarity and thus enabled the network to overcome the challenges of horizontal networks as suggested by Gladwell [17].

The analysis of the shared Communicative content also illustrates the interplay between the two logics of action, as the data analysis finds that content is based on both personalized and collective action frames. This is identified in how shared content echoes personal interpretations of the perceived common cause and inspire engagement in continuous co-creation of new content. The co-creation of novel content takes place in emerging online communities where disparate individuals from multiple contexts, with different ideas are brought together and start to collaborate. The importance of the community corroborates previous 
studies e.g. Yates \& Pacuette [39] and Seraj [32], as fostering collaboration potentially adds intellectual value [32] and help solve challenges [39]. These communities and their ability to foster emergent collaboration have blurred the line between individualism and collectivism. The line is blurred as engagement based on sharing content or endorsing others becomes an act of personal expression that simultaneously contributes to a perceived common cause as suggested by Bennett \& Segerberg [3] and Schneckenberg [30]. This blurred line is especially seen in the use of memes, as remixing memes that echo a perceived common cause is a way for actors to engage in emergent collaboration by personalizing content. In line with [37], we therefore consider memes a primary tool for communicating and mobilizing disparate actors in online communities. This was for example seen in how new memes e.g. \#IfTheyGunnedMeDown emerged as a way for disparate actors to personalize content, and to contribute to the joint effort of challenging how black people were portrayed in mainstream media, by sharing two contrasting images of oneself.

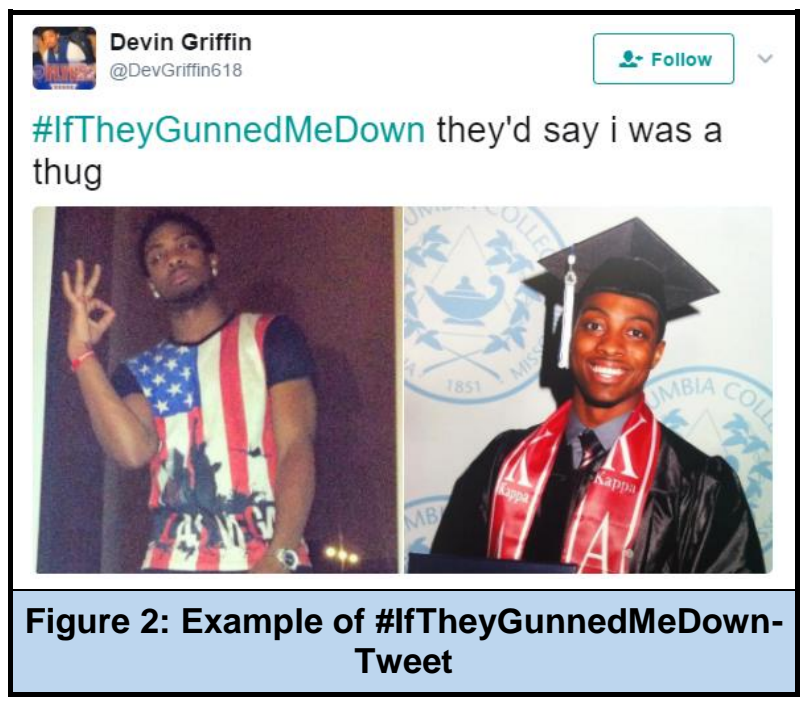

\#IfTheyGunnedMeDown became a way for actors to personalize content by easily imitating the shared content of others, which facilitated rapid diffusion across boundaries and illustrated how memes can become a catalyst for cultural developments as suggested by Wiggins \& Bowers [37]. This is however not only seen with memes, as protesting, sharing quotes, news, and other types of content that express solidarity also increase coherence within the community and foster emergent collaboration. They enable actors to self-validate their participation by remixing content that echoes perceived shared values and thereby not only pursue self-interests but also contribute to a common cause. The content shared by utilizing related hashtags was then, due to the perceived common cause associated within the \#BlackLivesMatter community. The community then functions as the context that legitimizes engagement, which in turn encourages the creation of new ways to remix all types of content and enable the personalization of content to contribute. The reuse of content is essential, as it enables the social networks to utilize recycled content to increase coherence as suggested by Wieczerzycki [36]. The increased coherence can then lead to reinforced beliefs in shared values and common causes that Sunstein [34] and Gladwell [17] identified as being essential for these large-scale communities to achieve anything. The ability to achieve anything is however also dependent on these social networks ability to move beyond the boundaries that define the homogeneous social network [34], which reaffirm the importance of the dynamic interplay between connective and collective action. Emergent collaboration is therefore dependent on the dynamic interplay, as individuals while pursuing their own self-interests contribute to a collective pursuit for something bigger than anyone could have achieved individually.

\subsection{Limitations and future research}

This paper is limited by the sample size which was available on Twitter at the time of data collection. The data was collected directly from the Twitter feed, which removes some complexity from the data. Future research should aim to collect data simultaneously in conjunction with developing instances of emergent collaboration, such as online social movements, in order to avoid limitations in data access. Additionally, our qualitative analysis, which relies on the available data, could be supplemented with other data collection efforts such as interviews and a more in-depth analysis of the available visual content (e.g., memes) and the shared images to further solidify the findings. Beyond the qualitative data analysis, it would have been interesting to conduct a network analysis to analyze the structure of the community, network density and centrality of certain themes.

This case study is furthermore limited as the impact of offline activism on the online presence of the \#BlackLivesMatter movement, and the influence of Facebook, YouTube and various other social media channels were not considered.

\section{Conclusion and implications}

This paper is aimed at unraveling the organizing elements of large-scale online communities that foster 
emergent collaboration. Drawing on the collective and connective action theory and other relevant literature, we advance a framework consisting of three organizing elements: structure, engagement and communicative content that are identified as crucial in investigating emergent online collaboration. Emergent collaboration is viewed as a process of interaction among actors present in online communities that may lead to collective action and united "we" through convergence and articulation of personal action frames into collective action frames and the construction of a collective identity.

The study contributes to existing research by further exploring the puzzle of how online communities achieve coherent organization and overcome the chaotic and unproductive nature of connective action.

The paper finds that the development of a hybrid structure that simultaneously incorporates elements of both logics of action is essential in supporting emergent collaboration. Characteristics of the connective action are seen in how emergent collaboration takes place in large-scale and fluid online communities. In these communities, actors engage in diverse ways as suggested by the five coding categories; raise awareness, offline events, antiauthorities, victimization, and collaboration. These communities constitute actors that contribute and validate the participation of others by remixing and personalizing the shared content within various similar and more homogenous social networks. This participation then fosters emergent collaboration, as the remixed content is deemed to echo a common cause. Characteristics of collective action are seen in how these social networks are defined by higher levels of homogeneity based on specific shared values. The increased homogeneity within these social networks indicates more coordinated collaboration based on a collective identity. The continuous reuse of content within the community stimulates interaction and mobilizes like-minded actors.

Fostering engagement in emergent collaboration through different forms of content is essential to achieve coherent organization within large-scale communities. The interplay between the two logics of action is crucial as it enables different forms of communication, including personalization of content and more collective framing. The replication of collective ideas through personalized content thereby enables actors to pursue their own self-interests and focus on short-lived and rapidly shifting issues while also moving as a collective. This inspires continuous engagement, which is essential in stimulating participation and thereby foster emergent collaboration within large-scale online communities.

\section{References}

[1] A. Altman, "Person of the Year: The Short List", 2016. http://time.com/time-person-of-the-year-2015-runner-upblack-lives-matter/

[2] A. Ardichvili, V. Page, and T. Wentling, "Motivation and barriers to participation in virtual knowledge-sharing communities of practice", Journal of knowledge management 7(1), 2003, pp. 64-77.

[3] W.L. Bennett, and A. Segerberg, "The logic of connective action: Digital media and the personalization of contentious politics", Information, Communication \& Society 15(5), 2012, pp. 739-768.

[4] W.L. Bennett, A. Segerberg, and S. Walker, "Organization in the crowd: peer production in large-scale networked protests", Information, Communication \& Society 17(2), 2014, pp. 232-260.

[5] R.E. Boyatzis, Transforming qualitative information: Thematic analysis and code development, sage, 1998.

[6] A. Chadwick, "Digital network repertoires and organizational hybridity", Political Communication 24(3), 2007, pp. 283-301.

[7] C.-M. Chiu, M.-H. Hsu, and E.T.G. Wang, "Understanding knowledge sharing in virtual communities: An integration of social capital and social cognitive theories", Decision support systems 42(3), 2006, pp. 1872 1888 .

[8] C. Cristancho, and E. Anduiza, "Connective action in european mass protest", workshop on Activist Social Media Communication, (2013).

[9] R. Dawkins, The selfish gene, Oxford university press, 2016.

[10] E. Day, "\#BlackLivesMatter: the birth of a new civil rights movement”, 2015.

https://www.theguardian.com/world/2015/jul/19/blacklivesm atter-birth-civil-rights-movement

[11] M. Diani, "The concept of social movement", The sociological review 40(1), 1992, pp. 1-25.

[12] K.M. Eisenhardt, "Building theories from case study research", Academy of management review 14(4), 1989, pp. $532-550$.

[13] N. Fenton, "Mediating solidarity", Global Media and Communication 4(1), 2008, pp. 37-57.

[14] S. Fournier, and L. Lee, "Getting brand communities right", Harvard business review 87(4), 2009, pp. 105-111.

[15] D. Freelon, C.D. McIlwain, and M.D. Clark, Beyond the hashtags:\# Ferguson,\# Blacklivesmatter, and the online 
struggle for offline justice, 2016.

[16] S. Gilbert, "Portraits of Participation: Exploring the Relationship between Social Motivators and Facets of Participation in a Twitter-based Community", Proceedings of the 50th Hawaii International Conference on System Sciences, (2017).

[17] M. Gladwell, "Small change", The New Yorker 4(2010), 2010, pp. 42-49.

[18] Guardian.com, "Black Lives Matter: birth of a movement", Guardian.com, 2017.

https://www.theguardian.com/us-news/2017/jan/17/black-

lives-matter-birth-of-a-movement

[19] Y. Hu, and Y. Hong, "Modeling Twitter Engagement in Real-World Events", Proceedings of the 50th Hawaii International Conference on System Sciences, (2017).

[20] H. Jenkins, R. Purushotma, M. Weigel, K. Clinton, and A.J. Robison, Confronting the challenges of participatory culture: Media education for the 21 st century, Mit Press, 2009.

[21] A.M. Kaplan, and M. Haenlein, "Users of the world, unite! The challenges and opportunities of Social Media", Business horizons 53(1), 2010, pp. 59-68.

[22] L.I. Labrecque, E. Markos, and G.R. Milne, "Online personal branding: processes, challenges, and implications", Journal of Interactive Marketing 25(1), 2011, pp. 37-50.

[23] M. Lim, "Framing Bouazizi:'White lies', hybrid network, and collective/connective action in the 2010-11 Tunisian uprising”, Journalism 14(7), 2013, pp. 921-941.

[24] N. Luo, M. Zhang, and W. Liu, "The effects of value cocreation practices on building harmonious brand community and achieving brand loyalty on social media in China", Computers in Human Behavior 48, 2015, pp. 492-499.

[25] C. Lutz, and C.P. Hoffmann, "The dark side of online participation: exploring non-, passive and negative participation", Information, Communication \& Society, 2017, pp. 1-22.

[26] M. Olson, Logic of collective action public goods and the theory of groups Rev. ed.., 1965.

[27] J.W. Pennebaker, "The secret life of pronouns", New Scientist 211(2828), 2011, pp. 42-45.

[28] L. Razmerita, K. Kirchner, and T. Nabeth, "Social media in organizations: leveraging personal and collective knowledge processes", Journal of Organizational Computing and Electronic Commerce 24(1), 2014, pp. 74-93.

[29] H.J. Schau, and M.C. Gilly, "We are what we post? Self-presentation in personal web space", Journal of consumer research 30(3), 2003, pp. 385-404.

[30] D. Schneckenberg, "Web 2.0 and the empowerment of the knowledge worker", Journal of knowledge management 13(6), 2009, pp. 509-520.

[31] A. Segerberg, and W.L. Bennett, "Social media and the organization of collective action: Using Twitter to explore the ecologies of two climate change protests", The Communication Review 14(3), 2011, pp. 197-215.

[32] M. Seraj, "We create, we connect, we respect, therefore we are: intellectual, social, and cultural value in online communities", Journal of Interactive Marketing 26(4), 2012, pp. 209-222.

[33] B. Stephen, "How Social Media Helps Black Lives Matter Fight the Power", Wired.com, 2015. https://www.wired.com/2015/10/how-black-lives-matteruses-social-media-to-fight-the-power/

[34] C.R. Sunstein, "The law of group polarization", Journal of political philosophy 10(2), 2002, pp. 175-195.

[35] Twitter Inc., "Twitter limits (API, updates, and following)", 2017. https://support.twitter.com/articles/15364

[36] M. Wieczerzycki, "The Wisdom of e-crowds: Can Masses Create Value?", International Journal of Management and Economics 51(1), 2016, pp. 47-62.

[37] B.E. Wiggins, and G.B. Bowers, "Memes as genre: A structurational analysis of the memescape", new media \& society $17(11), 2015$, pp. 1886-1906.

[38] S. Wright, "Populism and downing street e-petitions: connective action, hybridity, and the changing nature of organizing", Political Communication 32(3), 2015, pp. 414433.

[39] D. Yates, and S. Paquette, "Emergency knowledge management and social media technologies: A case study of the 2010 Haitian earthquake", International journal of information management 31(1), 2011, pp. 6-13.

[40] R.K. Yin, Case study research: Design and methods, Sage publications, 2013. 